\title{
Comunicação
}

\section{Diversidade genética entre populações de guarirobeiras no Estado de Goiás}

\author{
Edésio Fialho dos Reis ${ }^{1}$, Jefferson Fernando Naves Pinto ${ }^{1}$, Antônio Paulino da Costa Netto ${ }^{1}$, \\ Hildeu Ferreira da Assunção ${ }^{1}$, Danielle Fabíola Pereira da Silva ${ }^{1 *}$
}

\begin{abstract}
RESUMO
A guarirobeira é uma espécie de palmeira que produz o palmito amargo, muito apreciado na culinária do CentroOeste brasileiro, e que pode ser utilizada tanto em projetos paisagísticos, como na alimentação animal. No entanto, por falta de informações agronômicas sobre a referida espécie, as estratégias de cultivo comercial, de seleção e de melhoramento são dificultadas. Este trabalho teve como objetivo avaliar a divergência genética entre populações de guarirobeiras, de três municípios do Estado de Goiás, e quantificar a contribuição relativa de oito características na diversidade, utilizando procedimentos multivariados. Foram analisados 24 indivíduos provenientes de três populações, com número de indivíduos de três plantas com 30 e 36 meses de idade. As características avaliadas foram: diâmetro do estipe, número de folhas definitivas, altura da planta, comprimento da primeira folha verde, número de bainhas foliares e comprimento,, diâmetro da base e peso do palmito. A diversidade genética das populações foi avaliada pelos métodos de agrupamento de Tocher, com base na matriz de dissimilaridade, obtida pela distância euclidiana média padronizada e na análise por componentes principais com dispersão gráfica no plano cartesiano. Os resultados mostraram a existência de variabilidade genética, estimativas de herdabilidade de magnitude elevada para altura da planta, comprimento da folha, diâmetro do caule a $10 \mathrm{~cm}$ do solo, número de bainhas e diâmetro da base do palmito. A realização do agrupamento pelo método de Tocher, com base na matriz de dissimilaridade, promoveu a formação de oito grupos, evidenciando a influência da origem geográfica no agrupamento, e mostrou que a seleção com base em caracteres não destrutivos de alta correlação genética, como diâmetro do estipe e comprimento da folha, pode promover ganhos importantes na produção de palmito.
\end{abstract}

Palavras-chave: Syagrus oleracea (Mart.) Becc.; correlação; agrupamento; análise multivariada.

\begin{abstract}
\section{Genetic diversity among bitter palm populations in the state of Goiás}

Bitter palm is a palm tree species that produces bitter core, which is too appreciated in cooking and can be used in animal feeding, as well as in landscaping, but it is still little studied, which hinders strategies for its cultivation and breeding. The present work aimed at evaluating the genetic divergence among bitter palm populations of three municipalities of Goiás and quantifying the relative contribution of eight characteristics in the diversity, using multivariate procedures. Twenty-four individuals from three populations were analyzed, with individuals from three plants with 30 and 36 months of age. The characteristics evaluated were: stipe diameter, number of definitive leaves, plant height, length of first green leaf, number of leaf sheaths, length and weight of heart of palm, and diameter of heart of palm base. The genetic diversity of the populations was evaluated by Tocher's grouping method based on the dissimilarity matrix obtained by standardized mean Euclidean distance and the principal component analysis with graphical dispersion in the Cartesian plane. The results demonstrated the existence of genetic variability and heritability estimates of high
\end{abstract}

Submetido em 27/10/2016 e aprovado em 16/10/2017.

${ }^{1}$ Universidade Federal de Goiás, Programa de Pós-Graduação em Agronomia, Jataí, Goiás, Brasil. edesiofr7@gmail.com; jeffnaves@gmail.com; hildeu@yahoo.com.br; apcnetto@yahoo.com.br; daniellefpsilva@gmail.com

*Autora para correspondência: daniellefpsilva@gmail.com 
magnitude for plant height, leaf length, stalk diameter at $10 \mathrm{~cm}$ soil, number of heart of palm sheaths, and core diameter of heart of palm. The performance of the grouping by Tocher's method based on the dissimilarity matrix promoted the formation of eight groups, evidencing the influence of the geographical origin in the grouping and the selection in nondestructive characters of high genetic correlation as stalk diameter and leaf length can promote important gains in the production of heart of palm.

Key words: Syagrus oleracea (Mart.) Becc.; bitter palm; correlation; grouping; multivariate analysis.

\section{INTRODUÇÃO}

A guariroba (Syagrus oleracea (Mart.) J. Becc.) é uma planta nativa do Brasil, ocorrendo frequentemente nos estados da Bahia, Minas Gerais, Goiás, Mato Grosso do Sul e São Paulo. Apresenta como nomes comuns: patiamargosi, coqueiro amargoso, gueroba, guarirova, gueirova e amargoso, sendo que, das partes comestíveis, destaca-se o seu palmito ou broto terminal (Hiane et al., 2011).

Diversos tipos de palmeiras podem fornecer palmito de boa qualidade, que se diferenciam por precocidade, cor e sabores diferentes. O palmito da guarirobeira é rico nas enzimas peroxidase e polifenoloxidase e em compostos fenólicos, sendo susceptível ao escurecimento. Os fenóis são responsáveis também pelo gosto adstringente e amargo característico da guariroba (Jaime et al., 2007), o que a diferencia dos gêneros Euterpe (Açaí e Juçara) e Bactris (pupunheira). A maior parte do palmito de guariroba é do tipo caulinar (estipe macio) e a porção aproveitável pesa em média de 0,5 a $3 \mathrm{~kg}$ (Hiane et al., 2011).

A produção de guariroba vem ganhando espaço na agricultura goiana, graças ao seu sistema de produção apresentar baixo custo e bom rendimento, além de boa qualidade, sendo viável sua exploração. As perspectivas são animadoras para pequenas propriedades rurais, pela possibilidade de uso em sistemas agroflorestais e consórcio com culturas anuais de arroz, feijão e milho, além de ser muito importante no contexto de desenvolvimento regional e apresentar grande potencial econômico (Pinto et al., 2010).

Estudos sobre a divergência em plantas perenes têm sido realizados, frequentemente, com base em descritores botânicos, morfológicos e agronômicos, por não apresentarem custos elevados (Silva et al., 2014). No entanto, as interpretações desses dados têm, habitualmente, sido realizadas por análises univariadas, o que gera dificuldades na obtenção das estimativas de divergência e, consequentemente, na seleção de indivíduos desejáveis para intercruzamentos. Assim, as técnicas multivariadas têm-se mostrado úteis, por avaliarem o indivíduo em vários aspectos e proporcionar uma visão holística (Cruz, 2016).
A partir da caracterização de genótipos por meio de marcadores morfológicos, moleculares, coeficiente de parentesco e outros, as populações podem ser agrupadas pelos coeficientes de similaridade ou dissimilaridade e vários métodos podem ser utilizados na avaliação da diversidade genética, cuja escolha baseia-se na precisão desejada pelo pesquisador, na facilidade da análise e na forma como os dados foram obtidos (Rodrigues et al., 2010).

De acordo com relatos de Wagner Júnior et al. (2011) e Chagas et al, (2016), o uso de medidas da divergência genética, obtidas antes de que qualquer cruzamento seja realizado, poderá auxiliar o melhorista a concentrar seus esforços nas combinações mais promissoras, aumentando a eficiência dos programas de melhoramento.

De forma geral, são escassos os estudos de genética e melhoramento em espécies da família das Arecaceas, sendo isto um agravante em se tratando do gênero Syagrus (Pinto et al., 2012). Esse trabalho teve como objetivo avaliar a divergência genética entre populações de guarirobeiras e quantificar a contribuição relativa de oito características para a diversidade, utilizando procedimentos multivariados.

\section{MATERIAL E MÉTODOS}

O experimento foi conduzido na Universidade Federal de Goiás - Regional Jataí, sendo, as populações, oriundas de três municípios do Estado de Goiás: Jataí (latitude $17^{\circ}$ 52' 53"S e longitude de 51 42' 52"O); Caiapônia (latitude $6^{\circ} 51^{\prime} 00^{\prime \prime}$ S e longitude 51 50' 00" O) e Anicuns (latitude $16^{\circ} 49^{\prime} 00^{\prime \prime} \mathrm{S}$ e longitude $49^{\circ} 56^{\prime} 24^{\prime \prime} \mathrm{O}$ ), onde foram coletados os frutos de forma aleatória para produção das mudas.

As mudas foram produzidas em sacos plásticos de 12×20 cm e transplantadas para local definitivo aos 90 dias após emergência. Para o preparo das covas utilizaram-se $100 \mathrm{~g}$ da formulação NPK 5-15-5 por cova, sendo essa dose misturada ao solo antes do plantio. O plantio foi realizado no espaçamento $1 \mathrm{x} 1,5 \mathrm{~m}$, sendo todos os tratos culturais realizados de acordo com as recomendações para a cultura.

O experimento foi conduzido em delineamento em blocos ao acaso, com três repetições e seis plantas por par- 
cela provenientes de três municípios, totalizando 54 progênies. As populações foram agrupadas em três grupos, sendo cada grupo formado por oito progênies. O grupo 1 foi formado pelas progênies $1,2,3,4,5,6,7$ e 8; o grupo 2 pelas progênies $9,10,11,12,13,14,15$ e 16 e o grupo 3 pelas progênies $17,18,19,20,21,22,23$ e 24 constituídas, respectivamente, das três procedências Duas avaliações foram realizadas, a primeira em maio de 2006, aos 30 meses de idade das plantas, quando foram avaliadas as características diâmetro do estipe a 10 e $50 \mathrm{~cm}$ do solo (D10ca) e (D50ca), respectivamente, e número de folhas definitivas (NFDca).

A segunda avaliação para análises destrutivas deu-se no momento da colheita do palmito, aos 36 meses de idade. Assim, utilizou-se uma planta de cada parcela experimental, em todos os três blocos, totalizando três plantas de cada genótipo. Após a colheita, procederam-se às avaliações de altura da planta (APco), medida do nível do solo até a inserção da última folha completamente expandida; comprimento da primeira folha verde no momento da colheita, em cm (CFco); número de folhas definitivas (NFDco); diâmetro do estipe a 10 e a $50 \mathrm{~cm}$ do solo (D10co) e (D50co), em cm, respectivamente; número de bainhas foliares envolvendo o palmito (NBp); comprimento do palmito, em cm (CP); diâmetro da base do palmito, em cm (DBp) e peso do palmito, em gramas (PPg).

A diversidade genética das populações foi avaliada pelo método de agrupamento de Tocher, com base na matriz de dissimilaridade, obtida pela distância euclidiana média padronizada e pela análise por componentes principais com dispersão gráfica no plano cartesiano. O método de Tocher forma um grupo inicial com o par de indivíduos mais similares, identificados na matriz de dissimilaridade. A partir desse par é avaliada a possibilidade de inclusão de novos indivíduos, adotando-se o critério de que a distância média intragrupo deve ser menor que a distância média intergrupo (Cruz et al., 2011). A visualização gráfica da divergência genética foi realizada a partir da dispersão dos dois primeiros componentes principais. As análises estatístico-genéticas foram realizadas com o programa estatístico Genes (Cruz, 2016).

\section{RESULTADOS E DISCUSSÃO}

Os coeficientes de variação ambiental $(\mathrm{CVe})$ variaram de 18,61 a 67,49\% (Tabela 1). Observou-se que as estimativas de herdabilidade no sentido amplo apresentaram valores bastante variados, o que pode ser explicado pela expressão dos diferentes caracteres e pela desuniformidade da própria espécie, por ser incipientemente domesticada. Dentre essas características, as que apresentaram magnitudes de herdabilidade igual ou superior a $60 \%$, estão associadas ao momento da colheita e foram: altura da planta, comprimento da folha, diâmetro do caule a $10 \mathrm{~cm}$ do solo, número de bainhas no palmito e diâmetro da base do palmito, indicando, assim, boa representação do valor genético pelo valor fenotípico, o que propicia maior sucesso no processo seletivo para essas características.

Nascente (2003) caracterizou morfologicamente progênies de uma população de guariroba, oriunda de 106 municípios do Estado de Goiás, aos dois anos e meio. A média geral das progênies foi de seis folhas vivas por planta e $83 \%$ das plantas apresentaram entre duas e sete folhas vivas. A média geral do comprimento da circunferência da estipe, a $10 \mathrm{~cm}$ do solo, foi $43 \mathrm{~cm}$, o que corresponde a 13,69 cm de diâmetro, e a altura média da estipe foi $203 \mathrm{~cm}$. A população apresentou grande variabilidade com relação às características consideradas. Esses resultados corroboram os deste trabalho, em que foram observados, na avaliação com 36 meses, 7,69 folhas definitivas (variação de 7,78 a 7,71); diâmetros do estipe a $10 \mathrm{~cm}$ do solo de $12,82 \mathrm{~cm}$ (variação de 9,77 a $15,29 \mathrm{~cm}$ ); altura do estipe de $128,57 \mathrm{~cm}$ (variação de 98,10 a $164,60 \mathrm{~cm})$.

De acordo com Chagas et al. (2016), características que apresentam maior herdabilidade $\left(\mathrm{h}^{2}\right)$ determinam sua influência na próxima geração. Logo, têm maior facilidade de serem transmitidas para as próximas gerações, possivelmente por sofrerem menos influências dos fatores não genéticos, sendo, quando apresentam alta correlação com caracteres de interesse de baixa herdabilidade e difícil mensuração, viáveis para uso na seleção indireta.

Ainda, nessas características que apresentaram alta herdabilidade, verificaram-se alta razão entre os coeficientes de variação genético e o experimental, variando de 0,8417 a 1,1395, e valores elevados da acurácia na seleção de progênies, que variaram de 58,9 a 70,2\%.

Para as demais características, foram observados valores medianos de herdabilidade, como para diâmetro do caule a $10 \mathrm{~cm}$ do solo, na avaliação aos 30 meses; comprimento e peso do palmito. Esses resultados são interessantes do ponto de vista do melhoramento genético, pois, de acordo com relatos de Hiane et al. (2011) e Jaime et al. (2007), a maior parte do palmito de guariroba é do tipo caulinar (estipe macio) e a porção aproveitável do palmito encontrado no comércio pesa em média de 0,5 a $3 \mathrm{~kg}$. Os resultados obtidos neste trabalho para a característica peso do palmito apresentaram 0,28 de herdabilidade, indicando que esta característica tem uma influência considerável de fatores não genéticos.

Grandes variações quanto a valores de herdabilidade foram encontradas por Farias Neto et al. (2008), em estudo com açaí. Isto indica a possibilidade de sucesso de seleção nas características avaliadas neste trabalho. Logo, essa informação permite ao melhorista definir as características a serem avaliadas na seleção. 
Observa-se, na Tabela 2, que o diâmetro do caule a 10 cm, na avaliação aos 30 meses de idade da planta, só se correlacionou com número de folhas definitivas. Por outro lado, o diâmetro do caule a $50 \mathrm{~cm}$. na avaliação aos 30 meses de idade. correlacionou-se com praticamente todas as variáveis em estudo. No entanto, não é uma boa medida para seleção, pois apresenta baixa herdabilidade.

Assim, para espécies como a guariroba, em que a obtenção de seu produto principal, que é o palmito, leva à eliminação da planta, uma vez que não ocorre o perfilhamento ou rebrota, devem-se procurar caracteres não destrutivos que tenham alta associação com a produção do palmito e apresentem alta herdabilidade, possibilitando, então, a seleção indireta.

Neste contexto, a altura da planta, o comprimento da folha e o diâmetro do caule a $10 \mathrm{~cm}$ do solo, aos 36 meses de idade, momento em que foi realizada a colheita do palmito, pode ser de grande valia no processo de seleção, pois pode-se realizar a avaliação e preservar a planta como matriz para produção de frutos e propagação. Ainda é importante salientar a possibilidade de seleção

Tabela 1: Estimativas dos componentes de variância e dos parâmetros genéticos e fenotípicos para as progênies de guariroba nos descritores morfológicos estudados

\begin{tabular}{lrrrrrrrrrr}
\hline Descritores** & $\mathbf{V} \mathbf{g}^{*}$ & \multicolumn{1}{c}{ Ve* } & \multicolumn{1}{c}{$\mathbf{V f}^{*}$} & $\mathbf{h}^{2} \mathbf{g}^{*}$ & $\mathbf{C V g i} \% *$ & $\mathbf{C V e} *$ & $\mathbf{C V r}^{*}$ & Média Geral & Mínimo & Maximo \\
\hline D10ca & 1,88 & 2,22 & 4,09 & 0,46 & 15,63 & 21,72 & 0,720 & 8,76 & 8,12 & 9,36 \\
D50ca & 0,12 & 1,14 & 1,26 & 0,10 & 6,76 & 21,34 & 0,317 & 5,20 & 5,10 & 5,32 \\
NFDca & 0,02 & 0,95 & 0,97 & 0,02 & 2,35 & 18,61 & 0,126 & 5,26 & 5,24 & 5,30 \\
APco & 3265,27 & 225,32 & 3490,59 & 0,93 & 44,44 & 40,22 & 1,105 & 128,57 & 98,10 & 164,60 \\
CFco & 586,76 & 388,11 & 974,87 & 0,60 & 15,86 & 18,84 & 0,842 & 152,74 & 140,34 & 166,42 \\
NFDco & 0,02 & 2,40 & 2,42 & 0,01 & 1,89 & 20,21 & 0,094 & 7,69 & 7,68 & 7,71 \\
D10co & 21,26 & 1,39 & 22,65 & 0,94 & 35,95 & 32,46 & 1,108 & 12,82 & 9,77 & 15,29 \\
D50co & 0,94 & 11,79 & 12,73 & 0,07 & 12,90 & 47,08 & 0,274 & 7,50 & 7,18 & 7,68 \\
NBp & 1,48 & 0,91 & 2,40 & 0,62 & 20,80 & 24,32 & 0,855 & 5,85 & 5,25 & 6,59 \\
CP & 21,03 & 47,70 & 68,72 & 0,30 & 18,76 & 32,58 & 0,576 & 24,45 & 23,31 & 25,97 \\
DBp & 1,90 & 0,04 & 1,94 & 0,98 & 29,53 & 25,91 & 1,139 & 4,67 & 3,88 & 5,36 \\
PPg & 15518 & 38848 & 54367 & 0,28 & 37,42 & 67,49 & 0,554 & 332,92 & 291,65 & 402,54 \\
\hline
\end{tabular}

*: Variância genotípica (Vg), Variância residual (Ve), Variância fenotípica individual (Vf), Herdabilidade de parcelas individuais no sentido amplo, ou seja, dos efeitos genotípicos totais $\left(\mathrm{h}_{2} \mathrm{~g}\right)$, Coeficiente de variação genotípica (CVgi\%), Coeficiente de variação residual (CVe\%), Coeficiente de variação relativa (CVr), Média Geral das progênies, Média dos valores mínimos e Médias dos valores máximos.

**: D10ca e D50ca: diâmetro do estipe a 10 e $50 \mathrm{~cm}$ do solo; NFDca: número de folhas definitivas; APco: altura da planta; CFco: comprimento da primeira folha verde; NFDco: número de folhas definitivas; D10co e D50co: diâmetro do estipe a 10 e 50 cm do solo, respectivamente, em cm; NBp: número de bainhas foliares envolvendo o palmito; $\mathrm{CP}$ : comprimento do palmito em cm; DBp: diâmetro da base do palmito em cm; PPg: peso do palmito em gramas.

***: ca: avaliação feita aos 30 meses de idade; co: avaliação feita no momento da coleta do palmito.

Tabela 2: Estimativas de correlações genotípicas entre os descritores estudados em guariroba

\begin{tabular}{|c|c|c|c|c|c|c|c|c|c|c|c|}
\hline Descr.*** & D10 & D50 & NFD & APco & CFco & NFDco & D10co & D50co & NBp & $\mathrm{CP}$ & DBp \\
\hline D50ca & 0,31 & & & & & & & & & & \\
\hline NFDca & $0,43 *$ & $0,63 * *$ & & & & & & & & & \\
\hline APco & 0,06 & $0,71 * *$ & 0,35 & & & & & & & & \\
\hline CFco & 0,03 & $0,62 * *$ & $0,43 *$ & $0,84 * *$ & & & & & & & \\
\hline NFDco & 0,06 & $0,44^{*}$ & 0,12 & $0,78 * *$ & $0,69 * *$ & & & & & & \\
\hline D10co & $-0,01$ & $0,61 * *$ & $0,46^{*}$ & $0,83 * *$ & $0,83 * *$ & $0,71 * *$ & & & & & \\
\hline D50co & $-0,04$ & $0,53 * *$ & 0,26 & $0,82 * *$ & $0,78 * *$ & $0,68 * *$ & $0,82 * *$ & & & & \\
\hline NBp & 0,06 & 0,32 & 0,33 & 0,33 & 0,38 & $0,47^{*}$ & $0,41^{*}$ & 0,36 & & & \\
\hline $\mathrm{CP}$ & 0,23 & $0,49^{*}$ & $0,49 *$ & $0,64 *$ & $0,73 * *$ & $0,56 * *$ & $0,74 * *$ & $0,66 * *$ & $0,54 * *$ & & \\
\hline DBp & 0,31 & $0,40^{*}$ & 0,24 & $0,66 * *$ & $0,53 * *$ & $0,48^{*}$ & $0,51 *$ & $0,67 * *$ & $0,42 *$ & $0,62 * *$ & \\
\hline $\mathrm{PPg}$ & 0,21 & $0,50^{*}$ & 0,37 & $0,71 * *$ & $0,62 * *$ & $0,64 * *$ & $0,64 * *$ & $0,68 * *$ & $0,48^{*}$ & $0,56^{* *}$ & $0,84 * *$ \\
\hline
\end{tabular}

****: Significativo a 1 e $5 \%$ de probabilidade, pelo teste "t".

*** D10ca e D50ca: diâmetro do estipe a 10 e $50 \mathrm{~cm}$ do solo; NFDca: número de folhas definitivas; APco: altura da planta; CFco: comprimento da primeira folha verde; NFDco: número de folhas definitivas; D10co e D50co: diâmetro do estipe a 10 e 50 cm do solo, respectivamente, em cm; NBp: número de bainhas foliares envolvendo o palmito; $\mathrm{CP}$ : comprimento do palmito em $\mathrm{cm}$; DBp: diâmetro da base do palmito em cm; PPg: peso do palmito em gramas.

**** co: avaliação feita aos 30 meses de idade; Ca: avaliação feita no momento da coleta do palmito. 
indireta visando à redução do ciclo, pois por estarem correlacionados com os caracteres associados ao palmito, permitem ganhos que refletirão no tempo de permanência no campo, ao se fazer a seleção de plantas mais altas, com maior comprimento de folha e maior diâmetro na base. De acordo com Pinto et al. (2012), descritores como altura de planta e diâmetro do caule são importantes na caracterização de acessos de guariroba por apresentarem contribuições importantes na discriminação da divergência.

Com isso, pode-se facilitar o desenvolvimento de plantas mais uniformes, pois uma das maiores dificuldades do cultivo da espécie é sua grande heterogeneidade no ciclo e, neste sentido, de acordo com Cruz (2016), caracteres de alta herdabilidade e que tenham alta correlação genética com a produção, no caso deste trabalho avaliadas aos 36 meses, tornam-se de grande valia na seleção de plantas precoces.

Com base nos resultados de agrupamento, as progênies formaram dez grupos pelo método de otimização de Tocher (Figura 1). O número de grupos formados mostra a ampla variabilidade entre as progênies avaliadas, quando se considera o conjunto das características. Diferentemente, Silva et al. (2014) analisaram 179 indivíduos, pertencentes a 15 populações de pessegueiro e, por meio do agrupamento pelo método de Tocher, observaram que a partir das 13 características avaliadas foram formados quatro grupos, sendo que 12 das 15 populações estuda- das foram alocadas no mesmo grupo, indicando baixa variabilidade entre elas..

Esses resultados auxiliam no processo seletivo, pois além de valor genético elevado para caracteres de interesse, é importante estabelecer uma referência de tempo para um programa de melhoramento da espécie pautado no ciclo. Assim, as características como altura da planta, comprimento da folha e o diâmetro do caule a $10 \mathrm{~cm}$ do solo, aos 36 meses de idade da planta, momento em que foi realizada a colheita, devem ser considerados na indicação do material propagativo das progênies para constituir um campo de produção de frutos como material propagativo.

A implementação de campos de produção de material propagativo deve atrelar-se à boa performance da progênie para os caracteres de interesse e à estrutura de divergência genética com base no agrupamento. Assim, selecionando-se dez progênies para melhor performance quanto ao valor genético para altura da planta, aos 36 meses de idade, seriam indicadas as progênies: 1, 7, 14 e 15 (grupo I); 23 (grupo IV); 4 e 19 (grupo V); 2 (grupo VI); 22 (grupo VII) e 16 (grupo VIII). Para a característica comprimento da folha, aos 36 meses de idade: 14 e 15 (grupo I); 11 e 12 (grupo III); 23 (grupo IV); 4 e 19 (grupo V); 2 (grupo VI); 22 (grupo VII) e 16 (grupo VIII). Para a característica diâmetro do caule a $10 \mathrm{~cm}$ do solo, aos 36 meses de idade: 1 , 8 e 15 (grupo I); 12 (grupo III); 23 (grupo IV); 4 e 19 (grupo V); 2 (grupo VI); 22 (grupo VII) e 16 (grupo VIII). Com

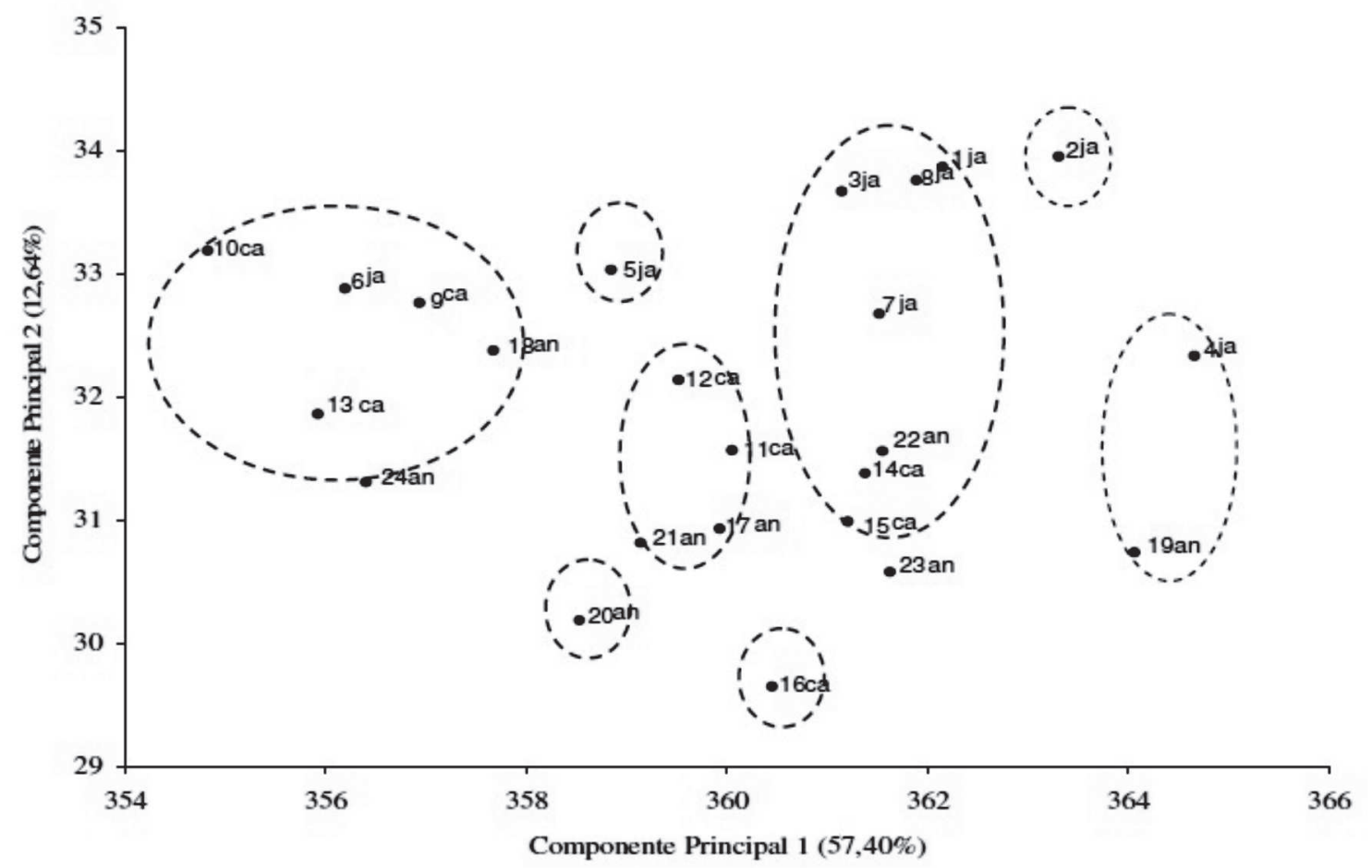

Figura 1: Dispersão das populações em relação aos dois primeiros escores dos componentes principais. Círculos com base no agrupamento pelo método de Tocher. As progênies são originárias de Jataí (ja); Caiapônia (Ca) e Anicuns (an). 
essa seleção, apenas a progênie três, que estaria alocada entre as dez de maior produção de palmito não seria selecionada.

Essa seleção levaria a um ganho esperado de 40,22\% na altura da planta, $11,81 \%$ no comprimento da folha, $29,34 \%$ no diâmetro do caule a $10 \mathrm{~cm}$ do solo e $20,68 \%$ na produção de palmito. $\mathrm{O}$ cruzamento ao acaso dessas progênies traria um efeito direto na redução do ciclo, na geração seguinte.

Por meio da análise dos componentes principais (Figura 1) observa-se que os dois primeiros explicaram 70,04\% da variação total. Os descritores de menor importância, por apresentarem maior coeficiente de ponderação nos últimos componentes principais, ou seja, aqueles que retêm a menor parte da variação total disponível, estão relacionados com a colheita e são: número de folhas, diâmetro do caule a $10 \mathrm{~cm}$ do solo, altura da planta e comprimento de folha. Isto indica que essas variáveis são descritores que discriminam pouco o material em estudo (Wagner Júnior et al., 2011), embora apresentem alta herdabilidade e boa acurácia, além de estarem correlacionadas com características importantes e destrutivas.

Na dispersão gráfica no espaço bidimensional, notase coerência com o agrupamento indicado pelo método de otimização de Tocher, que revela grupos com forte relação com a origem e a variabilidade para as progênies, no conjunto das variáveis em estudo, o que, de acordo com Rodrigues et al. (2010), pode favorecer o processo de seleção com ganhos nos diferentes caracteres.

Os resultados da avaliação permitem afirmar que, no conjunto das progênies em estudo, o processo de seleção pode conduzir a ganhos principalmente para ciclo, pois, nos caracteres que contribuem para sua redução, foi verificada herdabilidade elevada e a população em avaliação apresenta variabilidade, o que de acordo com Pinto $e t$ al. (2010), possibilita selecionar plantas com elevado potencial para fins de melhoramento genético.

\section{CONCLUSÕES}

Existe variabilidade nas progênies de guariroba em estudo;

A seleção para os caracteres altura da planta, comprimento da folha e diâmetro do caule podem levar a ganhos importantes na redução do ciclo e na produção de palmito.

\section{AGRADECIMENTOS}

Os autores agradecem ao CNPq (Conselho Nacional de Desenvolvimento Científico e Tecnológico), à CAPES (Coordenação de Aperfeiçoamento de Pessoal de Nível Superior) e à FAPEG (Fundação de Amparo à Pesquisa do Estado de Goiás), pelo apoio financeiro.

\section{REFERÊNCIAS}

Chagas K, Alexandre RS, Schmildt ER, Bruckner CH \& Faleiro FG (2016) Genetic diversity in genotypes of the sour passion fruit, based on the physical and chemical characteristics of the fruit. Revista Ciência Agronômica, 47:524-531.

Cruz CD (2016) Genes Software - extended and integrated with the R, Matlab and Selegen. Acta Scientiarum, 38:547-552.

Cruz CD, Ferreira FM \& Pessoni LA (2011) Biometria aplicada ao estudo da diversidade genética. Visconde do Rio Branco, Suprema. 620p.

Farias Neto JT, Resende MDV, Oliveira MSP, Nogueira OL, Falcão PN \& Santos NS (2008) Estimativas de parâmetros genéticos e ganhos de seleção em progênies de polinização aberta de açaizeiro. Revista Brasileira de Fruticultura, 30:1051-1056.

Hiane PA, Silva VCF, Filho MMR, Ramos MIL \& Campos RP (2011) Caracterização química do palmito guariroba in natura e congelado. Ciência Rural, 41:1012-1023.

Jaime NG, Moura CJ de \& Paula YO de (2007) Aceitação do palmito de guariroba [Syagrus oleracea (Mart.) Becc.] em conservas sob diferentes ácidos orgânicos. Pesquisa Agropecuária Tropical, 37:257-266.

Nascente AS (2003) caracterização morfológica de progênies nativas de guariroba (Syagrus oleracea Becc.) no estado de Goiás. Pesquisa Agropecuária Tropical, 33:113-115.

Pinto JFN, Reis EF, Costa-Netto AP, Pinto JFN, Assunção HF, Nunes HF (2012) Efeito de diferentes tratamentos na superação da dormência de sementes da palmeira Syagrus oleracea Becc. Cerne, 18:487-493.

Pinto JFN, Reis EF, Faleiro FG, Barbosa ECC, Nunes HF \& Pinto JFN (2010) Seleção de descritores vegetativos para caracterização de acessos de guariroba (Syagrus oleracea (Mart.) Becc.). Revista Brasileira de Fruticultura, 32:832-839.

Rodrigues HC de A, Rodrigues SR, Oliveira Junior O de, Ceccon G, Correa AM \& Abot AR (2010) Avaliação da diversidade genética entre acessos de mamoneira (Ricinus communis L.) por meio de caracteres morfoagronômicos. Revista Ceres, 57:773777.

Silva JO da C, Cremasco JPG, Matias RGP, Silva DFP da, Salazar AH \& Bruckner CH (2014) Divergência genética entre populações de pessegueiro baseada em características da planta e do fruto. Ciência Rural, 44:1770-1775.

Wagner Júnior A, Bruckner CH, Cantín CM, Sánchez MA \& Cruz CD (2011) Divergência genética entre progênies de Pessegueiro em Zaragoza, Espanha. Revista Brasileira de Fruticultura, 33:303-310. 